\title{
Sagittal mandibular osteotomy in a patient with Eisenmenger's syndrome: A case report
}

\section{Strzałkowa osteotomia żuchwy u pacjenta z zespołem Eisenmengera - opis przypadku}

\author{
Anton Filipskyi ${ }^{1, B-D}$, Yan Vares ${ }^{1, A, E, F}$, Tetyana Filipska ${ }^{2, A-C}$, Ruslan Kulinchenko ${ }^{3, B, C, E}$ \\ 1 Department of Oral and Maxillofacial Surgery, Danylo Halytsky Lviv National Medical University, Ukraine \\ ${ }^{2}$ Ward of Maxillofacial Surgery, Lviv Regional Clinical Hospital, Ukraine \\ ${ }^{3}$ Department of Prosthetic Dentistry, Danylo Halytsky Lviv National Medical University, Ukraine \\ A - research concept and design; $\mathrm{B}$ - collection and/or assembly of data; $\mathrm{C}$ - data analysis and interpretation; \\ $D$ - writing the article; $E$ - critical revision of the article; $F$ - final approval of the article
}

Address for correspondence

Anton Filipskyi

E-mail:anton.flipskyi@gmail.com

\section{Funding sources}

None declared

Conflict of interest

None declared

\section{Acknowledgements}

The authors express their deepest gratitude to cardiac surgeon - Mykola Konyk and Vitaliy Petrov, anesthesiologists - Boris Kokoyachuk and Oleg Gorodetsky, oral surgeon - Volodymyr Semyriak, and nurse - Natalia Boyko for their help in treating the patient and in preparing the material for publication.

Received on July 23, 2019

Reviewed on September 20, 2019

Accepted on 0ctober 18, 2019

Published online on February 21, 2020

Cite as

Filipskyi A, Vares Y, Filipska T, Kulinchenko R. Sagittal mandibular osteotomy in a patient with Eisenmenger's syndrome: A case report. Dent Med Probl. 2020;57(1):111-116. doi:10.17219/dmp/113206

DOI

$10.17219 / \mathrm{dmp} / 113206$

Copyright

○) 2020 by Wroclaw Medical University

This is an article distributed under the terms of the

Creative Commons Attribution 3.0 Unported License (CC BY 3.0)

(https://creativecommons.org/licenses/by/3.0/)

\section{Abstract}

The various abnormalities of occlusion cause significant discomfort to the patient suffering from them. Currently, the surgical treatment of malocclusion in healthy patients is a routine process. The situation is completely different when the patient has a serious disease of the respiratory or cardiovascular system - a condition which may contraindicate such treatment.

A 30-year-old female patient, with a class III skeletal defect (open bite and progeny) and Eisenmenger's syndrome was chosen as a clinical case. The DDS-Pro software was selected to plan the operation. The bilateral sagittal split osteotomy of the mandible was selected as the method of surgery. At the time of the initial examination, the patient had been denied surgical treatment several times in several other clinics. Before the treatment began, the patient underwent intensive preparation in the cardiac surgery unit for 2.5 months. Using the software, a surgical intervention was planned with the production of a surgical template. The operation was then performed; the treatment period was unremarkable. The resulting occlusion and changes in the shape of the face fully met the patient's psychological and esthetic expectations.

In conclusion, a complicated cardiovascular pathology does not al ways deprive patients with malocclusion of the possibility to undergo surgical treatment.

Key words: orthognathic surgery, malocclusion, progeny, Eisenmenger's syndrome, osteotomy of the mandible

Słowa kluczowe: chirurgia ortognatyczna, wada zgryzu, progenia, zespół Eisenmengera, osteotomia żuchwy 


\section{Introduction}

The human face has always received special consideration as a social signal which performs both informative and communicative functions. Unfortunately, the human face may be distorted by the presence of various congenital skeletal deformities, such as bite anomalies. The appearance of congenital abnormalities, especially in the maxillofacial area, is caused by different risk factors or genetic disorders during prenatal development. ${ }^{1}$ These disorders may be the source of esthetic and psychological discomfort.

However, the presence of concomitant - most often congenital - somatic pathologies in orthognathic patients greatly reduces their chances of receiving any necessary surgical treatment in general, and the correction of facial defects in particular. These are mostly the diseases of the respiratory and cardiovascular systems. The presence of one of these pathologies increases to a great extent the risk of nonsurgical bleeding and complications during general anesthesia. ${ }^{2}$ Moreover, these are highrisk patients for small clinics and they require treatment in large hospitals, equipped with full-sized resuscitation departments. The situation is further complicated by the fact that orthognathic surgery is considered a medical procedure, and not urgent care. It therefore depends on the implementation of the scheduled interventions and may be delayed indefinitely.

Eisenmenger's syndrome is a life-threatening condition, requiring careful medical monitoring. It is a congenital cardiac defect, commonly caused by a shunt between the 2 ventricles of the patient's heart. Eisenmenger's syndrome occurs when the increased pressure of the blood flow in the lung becomes so great that the direction of the blood flow through the shunt reverses. Oxygen-poor blood from the right side of the heart flows into the left side of the heart and is pumped throughout the patient's body, causing insufficient oxygen supply to all organs and tissues. ${ }^{3}$

Today, thanks to the development of medical science, surgical treatment to correct the facial shape and size has become a routine process. Modern orthognathic surgery enables complex interventions, consisting of diagnostic and planning measures, surgery, and patient rehabilitation. Currently, the standard interventions for bite correction include the Le Fort I osteotomy of the maxilla, the bilateral sagittal osteotomy of the mandible and the compression-distraction techniques. ${ }^{4}$ It should also be noted that osteotomy is less costly for the patient than the compression-distraction techniques, being at the same time equally effective; due to the intraoral surgical approach, it does not distort the patient's face and is less time-consuming than the compression-distraction techniques. The bilateral osteotomy of the mandible has been recognized as an excellent technique for the correction of severe open-bite cases when the patient has a normally developed mandible and no indication for bimaxillary osteotomy. ${ }^{4,5}$

Planning is an important and precise part of such interventions. After this stage, the surgeon knows exactly which bones to remodel and how to proceed in order to achieve the best results. ${ }^{6,7}$

Taking into account all of the above, this article presents our experience using a multidisciplinary approach to the orthognathic treatment of patients with maxillofacial malformations in combination with a severe concomitant pathology.

\section{Case report}

A young woman, aged 30, visited our clinic in October 2017. She had been diagnosed with congenital open bite (a class III skeletal facial deformity, characterized by a significant esthetic and functional defect) as well as Eisenmenger's syndrome with functional class II-III pulmonary hypertension. The patient had been denied surgical treatment several times in other clinics due to the complexity of the deformity and the presence of severe concomitant diseases. A thorough examination by our team revealed that it was possible to perform an orthognathic operation after proper preparation and planning. Written consent was given. The patient was examined by a psychologist and her psychological state was defined as satisfactory. Throughout the preparation phase, she remained under the supervision of a cardiologist and a cardiac surgeon. She underwent oxygen therapy and was treated with sildenafil (Strondex ${ }^{\circledR}$; Microkhim Pharmaceuticals Ltd., Rubizhne, Ukraine). Warfarin, which she ingested daily, was discontinued in order to increase blood coagulation 3 weeks before surgery and 5 days after. At the beginning of the preparation phase, the thromboplastin sensitivity, measured as the International Normalized Ratio (INR), was 4.1. A re-examination was carried out 2.5 months later. As INR was found to be 1.8 , we decided that the patient was ready for surgery (Fig. 1,2).

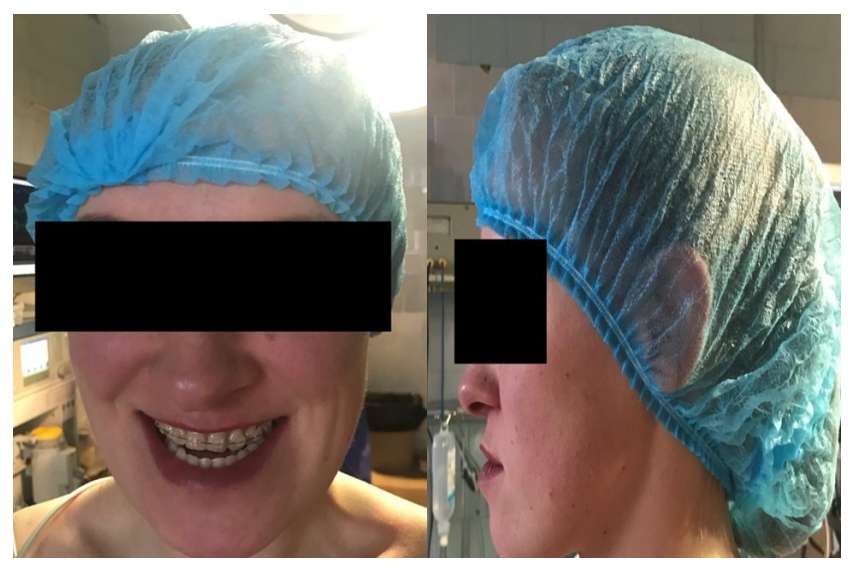

Fig. 1. Appearance of the patient's face before osteotomy 


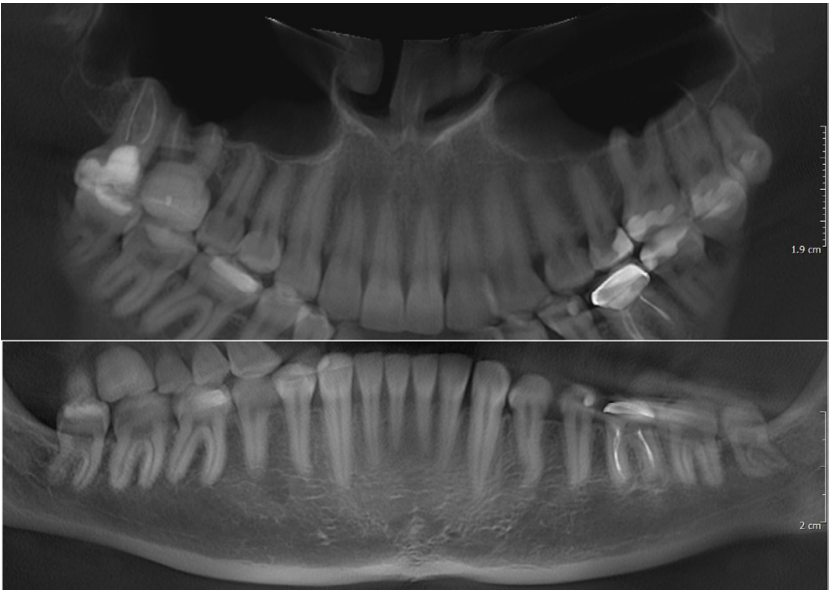

Fig. 2. The patient's orthopantomogram (OPG) before osteotomy

For virtual intervention planning, we used the DDSPro software from Digital Dental Services ${ }^{\circledR}$ (London, UK), which simulates operations with a high degree of accuracy and creates surgical templates that can be printed on a three-dimensional (3D) printer. The choice of the planning software was not random. Our team has successfully used the DDS-Pro software for 3 years. ${ }^{8}$ The $1^{\text {st }}$ step consisted of scanning the cast models of the patient's upper and lower jaws with a 3D scanner. These files, along with pre-operation spiral computed tomography $(\mathrm{CT})$ with a slice thickness of $0.5 \mathrm{~mm}$, were loaded into the DDS-Pro software, where a 3D skull model was created (Fig. 3). The simulation of bilateral sagittal split osteotomy was performed according to the abovementioned technique, moving the mandible backward $-7 \mathrm{~mm}$ to the right, $4 \mathrm{~mm}$ to the left - with a simultaneous left rotation of $5^{\circ}$ and $2^{\circ}$ upward. The resulting occlusion was verified (Fig. 4). All of the fragments were fixed together and a virtual 3D bite template was created (Fig. 5). A new preoperative 3D skull model was created for the patient and the surgical template was checked virtually (Fig. 6). The procedure was printed out, and the template was tested on the cast models (Fig. 7) and in the patient's oral cavity, on both the maxilla and mandible.

Subsequently, the operation - the bilateral sagittal split osteotomy of the mandible (using the Obwegeser II technique) with the single-stage removal of teeth 38 and 48 - was performed in the cardiac surgery unit under endotracheal anesthesia using sevoflurane gas. After the mandible was incised, the tooth row in each jaw was reduced to the expected occlusion position using

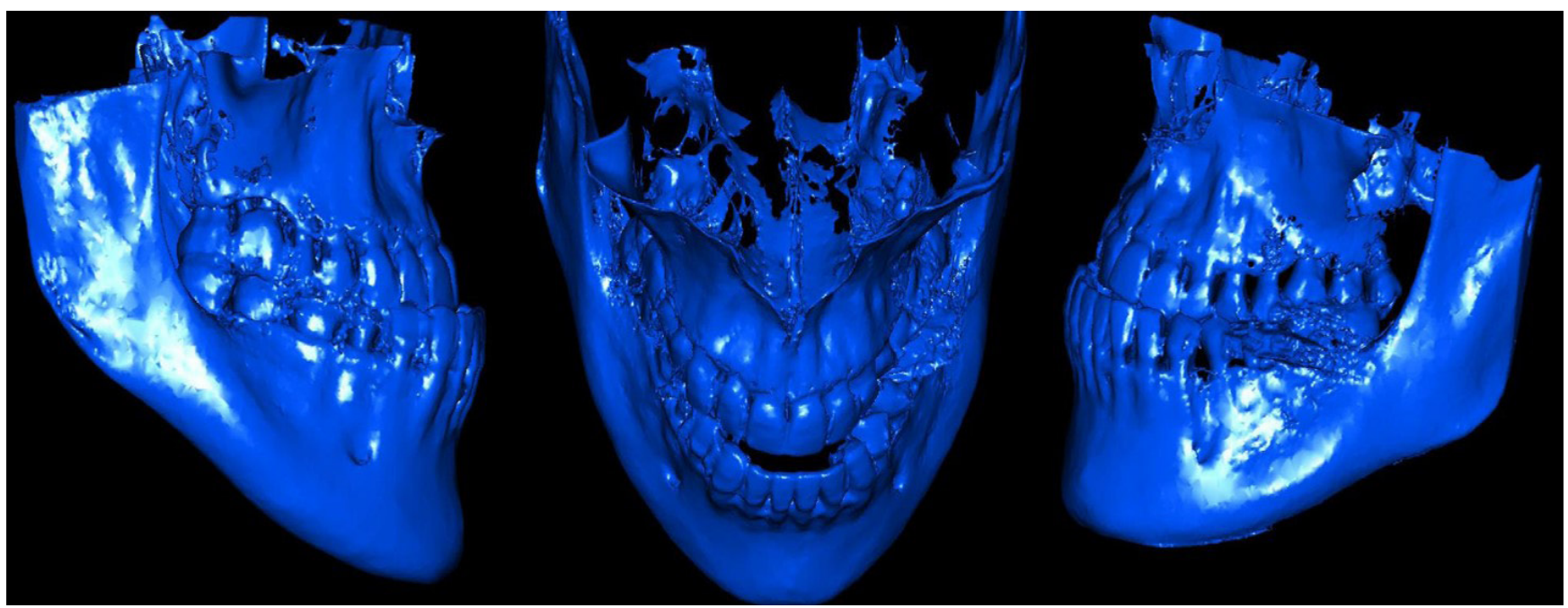

Fig. 3. The patient's initial three-dimensional (3D) skull model (right, top and left views)

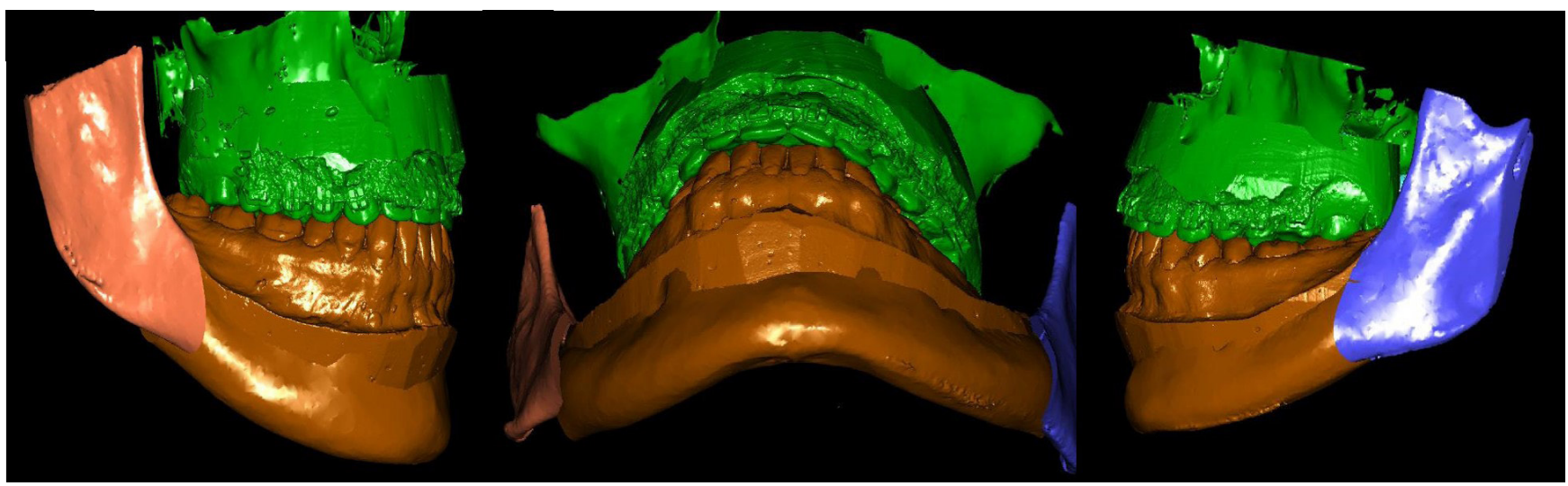

Fig. 4. Simulation of the surgical intervention (right, top and left views) 


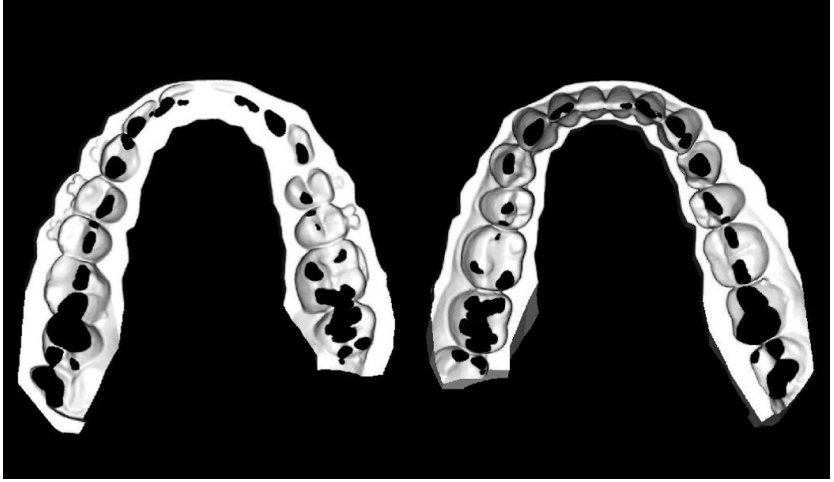

Fig. 5. Surgical template

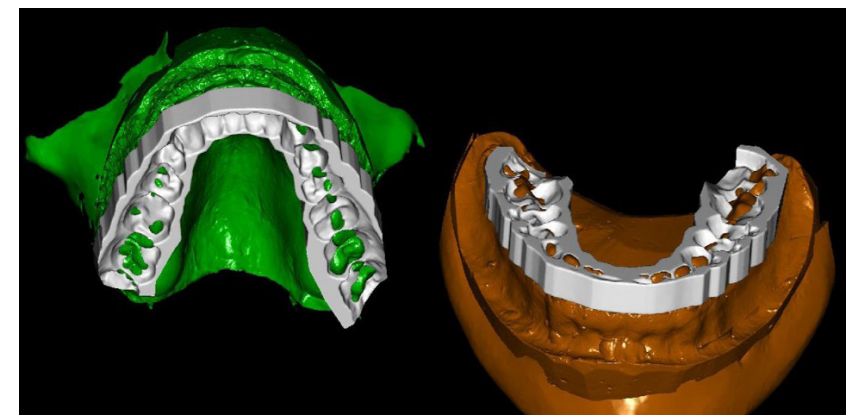

Fig. 6. Overlaying the surgical template on the 3D model

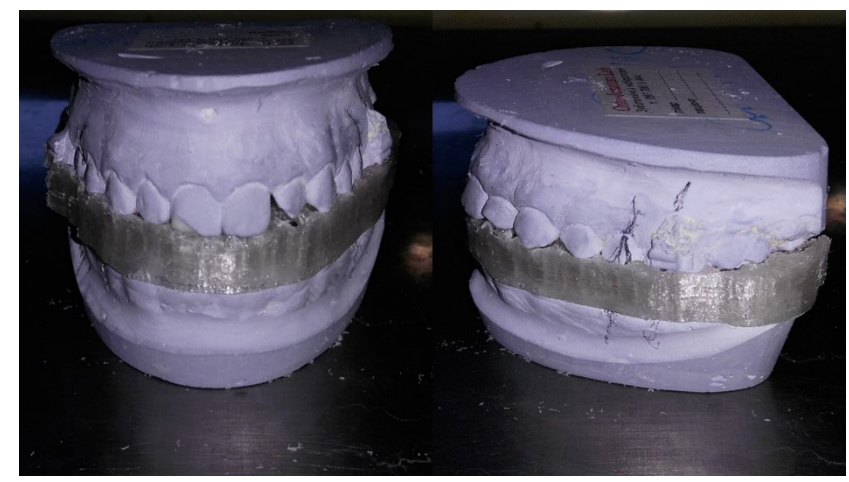

Fig. 7. Surgical template on preoperative models

the prepared template. In our case, mandibular fixation was performed according to Champy et al., using 2.0- $\mathrm{mm}$ miniplates and screws produced within the IRENE $^{\circledR}$ OsteoMed system (Tianjin Zhengtian Medical Instruments Co., Ltd., Tianjin, China). ${ }^{9}$ The IRENE intermaxillary fixation screws with orthodontic chain elastics were used for maxillo-mandibular fixation in the postoperative period.

The postoperative treatment period was unremarkable. The patient was under strict observation in the intensive care unit for the first 10 days following the surgery. On day 20, the patient was discharged and assigned post-hospital follow-up. The postoperative orthopantomogram (OPG) and photos of the patient's face were taken (Fig. 8,9). The resulting occlusion and changes in the facial shape fully met the patient's psychological and esthetic expectations.

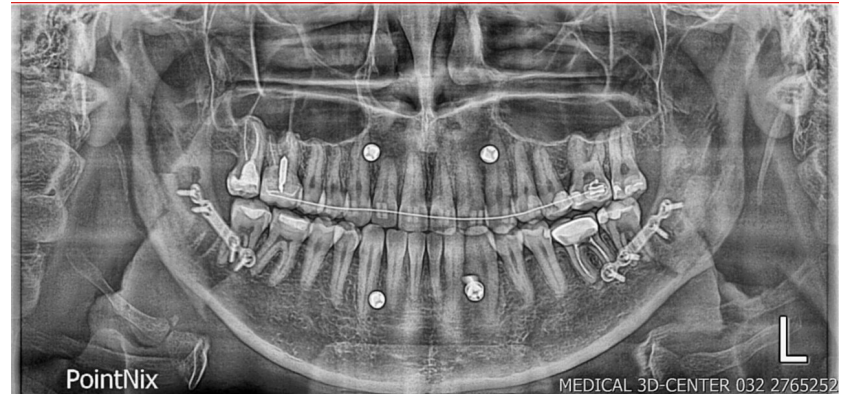

Fig. 8. The patient's postoperative OPG

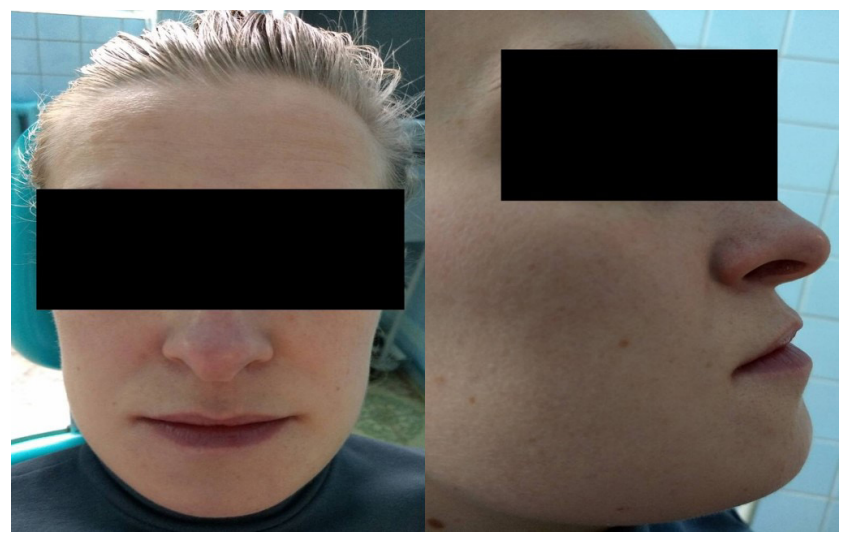

Fig. 9. Appearance of the patien't face (frontal and profile views) 3 weeks after surgery

The $1^{\text {st }}$ follow-up examination of the results was carried out 4 months after the orthognathic surgery. No deviations or complications were detected (Fig. 10). The final follow-up was conducted in May 2019 (15 months after the surgery). The patient did not notice any changes in bite. She was satisfied with the esthetic and functional outcome (Fig. 11). The clinical examination showed stable fixed occlusion throughout the dental arch. No pathological mobility was observed in the osteotomy area. The subsequent OPG showed healing at the osteotomy sites; miniplates and screws were fixed and stable (Fig. 12). The patient's follow-up continues.

Our study was conducted in accordance with the principles of the Declaration of Helsinki and the relevant laws of Ukraine, and it was approved by the Commission of Ethics of Danylo Halytsky Lviv National Medical University in Ukraine (Protocol No. 6/2019).

\section{Discussion}

Before the examination, we conducted a literature search for reports on the combined effects of maxillofacial and cardiovascular pathologies. As expected, there was not much information. We found only a few articles, but none were devoted to orthognathic patients with Eisenmenger's syndrome. Hupp presented a report on the successful treatment of a maxillary hemangioma using embolization in a patient with Eisenmenger's syndrome. ${ }^{10}$ 


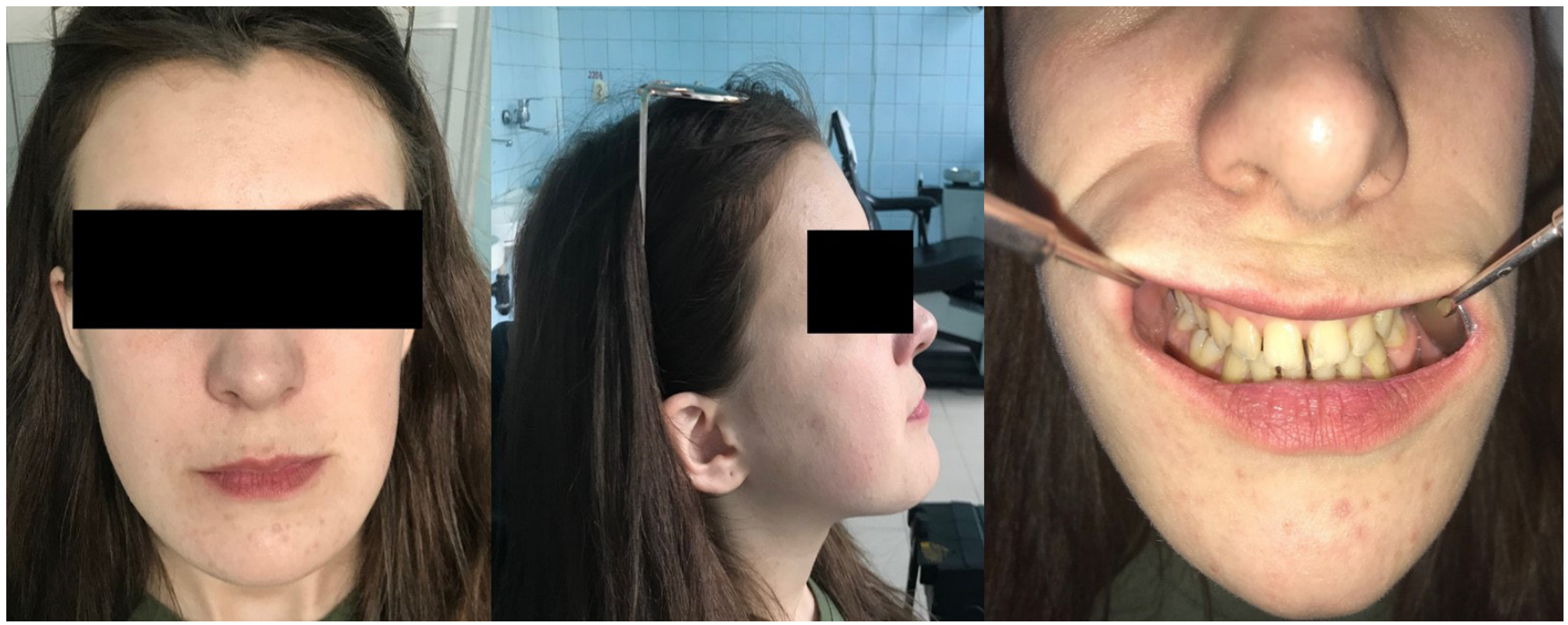

Fig. 10. The patient's face (frontal and profile views) and bite 4 months after surgery

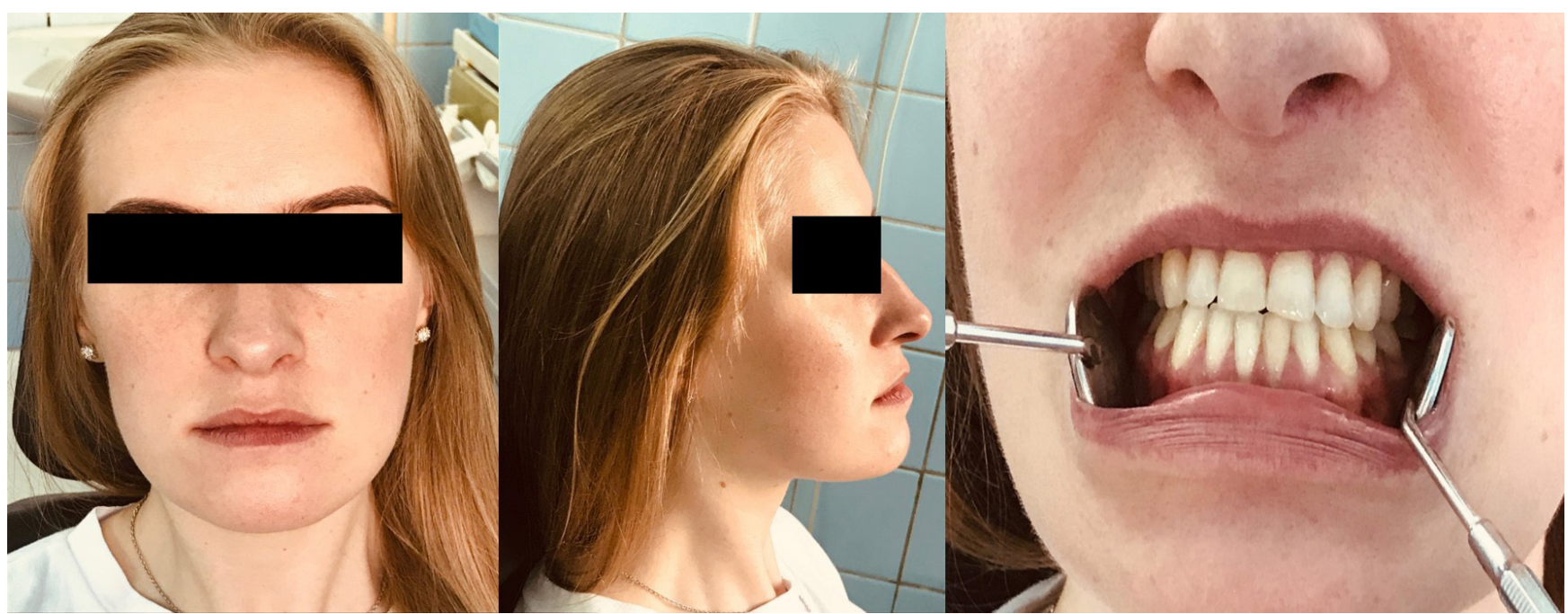

Fig. 11. The patient's face (frontal and profile views) and bite 15 months after surgery

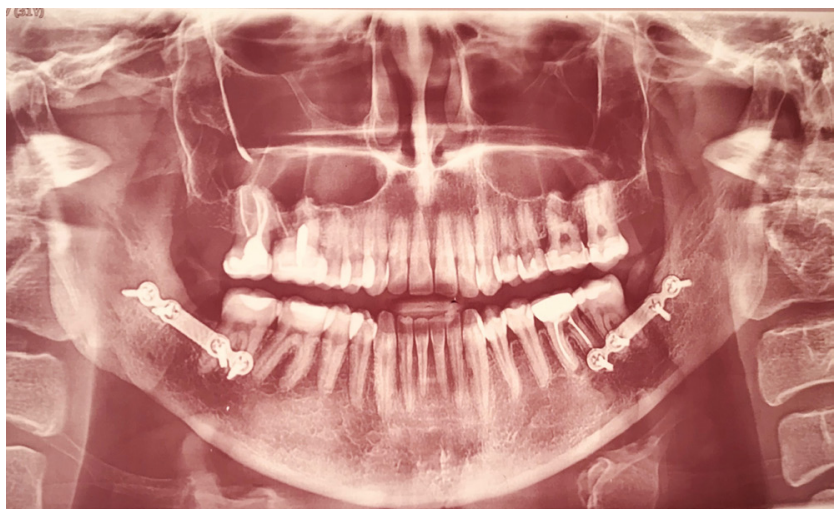

Fig. 12. The patient's OPG on the $15^{\text {th }}$-month follow-up visit

The author mentioned that in this particular case, the presence of Eisenmenger's syndrome added an challenge to the administration of anesthesia, but the operation and anesthesia were performed without complications. ${ }^{10}$ Raines et al. presented a report on the successful outcomes of various non-cardiac surgeries performed on 12 patients with Eisenmenger's syndrome using different types of anesthesia. ${ }^{11}$ The authors emphasize that anesthesia can be safe when different types of anesthesia and medication are applied. In their opinion, the expected mortality rate for patients undergoing non-cardiac surgery may be up to $10 \%$, which is lower than the mortality rate for parturient women after birth or cesarean section. ${ }^{11}$ Another group of surgeons presented the case of a 38-year-old female who was admitted with cardiac failure and Eisenmenger's syndrome, and underwent total abdominal hysterectomy. ${ }^{12}$ She was stabilized preoperatively with digoxin and diuretics. She was successfully managed with general anesthesia, the neuraxial blockade for pain relief, and perioperative bronchodilators and oxygen therapy. ${ }^{12}$ This information was good news for our team. After the careful analysis of the abovementioned studies, we reached a consensus on surgical planning and organization.

The issue of which surgical technique to use was easier to resolve: we decided on the standard technique. The advantages of the selected method are described below. 
For example, in their study of 2 groups of patients treated with osteotomy and distraction, Van Strijen et al. convincingly proved that distraction osteogenesis required a longer operation time (by $37 \%$ on average), but 1 day less of hospital stay than bilateral sagittal split osteotomy. ${ }^{13}$ The surgical cost of distraction osteogenesis was $36 \%$ higher than in the case of conventional sagittal split osteotomy. ${ }^{13}$ Baas et al. mentioned that patients experienced more pain after distraction osteogenesis, required more analgesics in the postoperative period and had more infections than the bilateral sagittal split osteotomy group. ${ }^{14}$ Moreover, Vos et al. reported a lack of significant differences in mandibular stability a year after treatment between 2 groups of patients where remodeling was performed - with bilateral sagittal osteotomy in one group and using the distraction technique in the other. ${ }^{15}$

It is clear that osteotomy requires surgeons to damage jaw integrity, i.e., to create an artificial fracture; it is extremely important to choose the appropriate technique and tool for fixation. This aspect becomes even more important when bilateral osteotomy is performed; 2 fractures require equally reliable fixation. In their study, Collins et al. compared standard 2.0-mm monocortical plates with 2.0-mm locking plates in the treatment of mandible fractures. ${ }^{16}$ They concluded that the mandible fractures treated with $2.0-\mathrm{mm}$ locking plates and standard 2.0-mm plates presented similar short-term complication rates. Accordingly, our decision on the choice of the surgical technique was simple and definite.

Summarizing all of the above, we can say that the presence of complicated cardiovascular pathologies should not deprive patients with malocclusion of the possibility of undergoing surgical treatment. A multidisciplinary approach to the preoperative preparation of patients with cardiovascular diseases and dentoalveolar anomalies is effective, and can reduce the number of patients who are refused for orthognathic surgery.

\section{ORCID iDs}

Anton Filipskyi (1) https://orcid.org/0000-0001-5682-9684

Yan Vares (i) https://orcid.org/0000-0002-1779-1107

Tetyana Filipska (1) https://orcid.org/0000-0001-7839-6621

Ruslan Kulinchenko [1] https://orcid.org/0000-0002-0424-4841

\section{References}

1. Houpt MI. Growth of the craniofacial complex of the human fetus. Am J Orthod Dentofacial Orthop. 1970;58(4):373-383.

2. Gwinnutt CL. Lecture Notes: Clinical Anaesthesia. $3^{\text {rd }}$ ed. Hoboken, NJ: Wiley-Blackwell; 2008:9-15,26-31.

3. Eisenmenger syndrome. https://www.mayoclinic.org/diseasesconditions/eisenmenger-syndrome/symptoms-causes/syc-20350580. Published August 9, 2018. Accessed March 31, 2019.

4. Bloomquist DS, Lee JJ. Principles of mandibular orthognathic surgery. In: Miloro M, Ghali GE, Larsen PE, Waite PD, eds. Peterson's Principles of Oral and Maxillofacial Surgery. $2^{\text {nd }}$ ed. London, UK: BC Decker Inc.; 2004:1135-1179.

5. Kwon TG, Na KM, Lee SH. Obwegeser Il osteotomy (transoral angle osteotomy) for open bite with skeletal class III deformity. J Craniomaxillofac Surg. 2014;42(7):1382-1388.

6. Pessa JE. The potential role of stereolithography in the study of facial aging. Am J Orthod Dentofacial Orthop. 2001;119(2):117-120.
7. Santoro M, Jarjoura K, Cangialosi TJ. Accuracy of digital and analogue cephalometric measurements assessed with the sandwich technique. Am J Orthod Dentofacial Orthop. 2006;129(3):345-351.

8. Vares YE, Got IM, Filipskyi AV, Filipska TA. Application of the DDS PRO software for planning of bilateral sagittal split osteotomy of the mandible: Clinical case description [in Ukrainian]. Acta Med Leopol. 2017;23(4):40-45.

9. Champy M, Loddé JP, Schmitt R, Jaeger JH, Muster D. Mandibular osteosynthesis by miniature screwed plates via a buccal approach. J Maxillofac Surg. 1978;6(1):14-21.

10. Hupp JR. Superselective angiography with digital subtraction and embolization of a maxillary hemangioma in a patient with Eisenmenger's syndrome. J Oral Maxillofac Surg. 1986;44(11):910-916.

11. Raines DE, Liberthson RR, Murray JR. Anesthetic management and outcome following noncardiac surgery in nonparturients with Eisenmenger's physiology. J Clin Anesth. 1996;8(5):341-347.

12. Puri GD, Pradhan A, Kumar B, Hegde HV, Singh A, Prasad GRV. Anaesthetic management of a patient with Eisenmenger syndrome for lower abdominal surgery. Curr Anaesth Crit Care. 2011;1(1):51-53.

13. Van Strijen PJ, Breuning KH, Becking AG, Perdijk FB, Tuinzing DB. Cost, operation and hospitalization times in distraction osteogenesis versus sagittal split osteotomy. J Craniomaxillofac Surg. 2003;31(1):42-45.

14. Baas EM, van Gemert BP, Bierenbroodspot F, Milstein DM, de Lange J. Patient discomfort and other side effects after bilateral sagittal split osteotomy or distraction osteogenesis of the mandible: A randomized clinical trial. Int J Oral Maxillofac Surg. 2015;44(9):1119-1124.

15. Vos MD, Baas EM, de Lange J, Bierenbroodspot F. Stability of mandibular advancement procedures: Bilateral sagittal split osteotomy versus distraction osteogenesis. Int J Oral Maxillofac Surg. 2009;38(1):7-12.

16. Collins CP, Pirinjian-Leonard G, Tolas A, Alcalde R. A prospective randomized clinical trial comparing $2.0-\mathrm{mm}$ locking plates to 2.0-mm standard plates in treatment of mandible fractures. J Oral Maxillofac Surg. 2004;62(11):1392-1395. 